\author{
Resume \\ Definision and explanation of the operating system structure \\ Dewi Ratna Sari \\ 195120021 \\ UNIVERSITAS MITRA INDONESIA \\ Dewiratnasari.student@umitra.ac.id
}

\begin{abstract}
ABSTRAK
Suatu sistem operasi modern merupakan suatu sistem yang besar dan kompleks sehingga strukturnya harus dirancang dengan hati-hati dan saksama supaya dapat berfungsi seperti yang diinginkan serta dapat dimodifikasi dengan mudah.

Struktur sistem operasi merupakan komponen-komponen sistem operasi yang dihubungkan dan dibentuk di dalam kernel.

Ada beberapa struktur sistem operasi dan pernah dicoba, diantaranya sebagai berikut:

Sistem monolithic, Sistem lapisan, Mesin virtual, Model client server, Referensi
\end{abstract}

KATA KUNCI : Struktur sistem operasi 


\section{Section 01}

\section{A. PENDAHULUAN}

Sistem komputer modern yang semakin komplek dan rumit memerlukan sistem operasi yang dirancang dengan sangat hati-hati agar dapat berfungsi secara optimum dan mudah untuk dimodifikasi.

Struktur sistem operasi merupakan komponen-komponen sistem operasi yang dihubungkan dan dibentuk di dalam kernel.

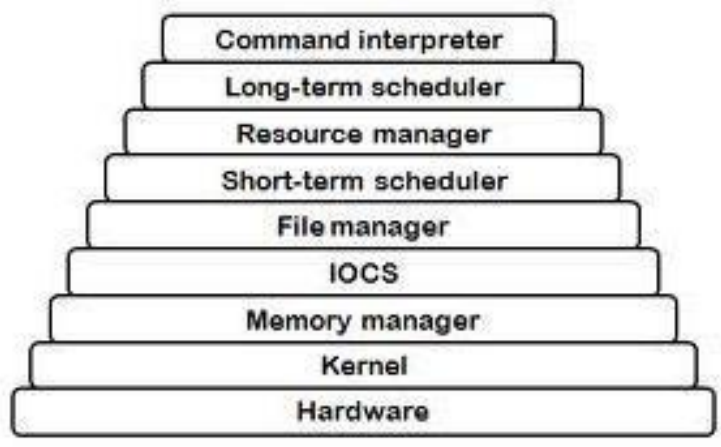

\section{B. PEMBAHASAN /STUDI KASUS}

Ada beberapa struktur sistem operasi dan pernah dicoba, diantaranya sebagai berikut:

\section{A. SISTEM MONOLITIK}

Sistem monolitik merupakan struktur sistem operasi sederhana yang dilengkapi dengan operasi "dual" pelayanan \{sistem call\} yang diberikan oleh sistem operasi. Model sistem call dilakukan dengan cara mengambil sejumlah parameter pada tempat yang telah ditentukan sebelumnya, seperti register atau stack dan kemudian mengeksekusi suatu intruksi trap tertentu pada monitor mod

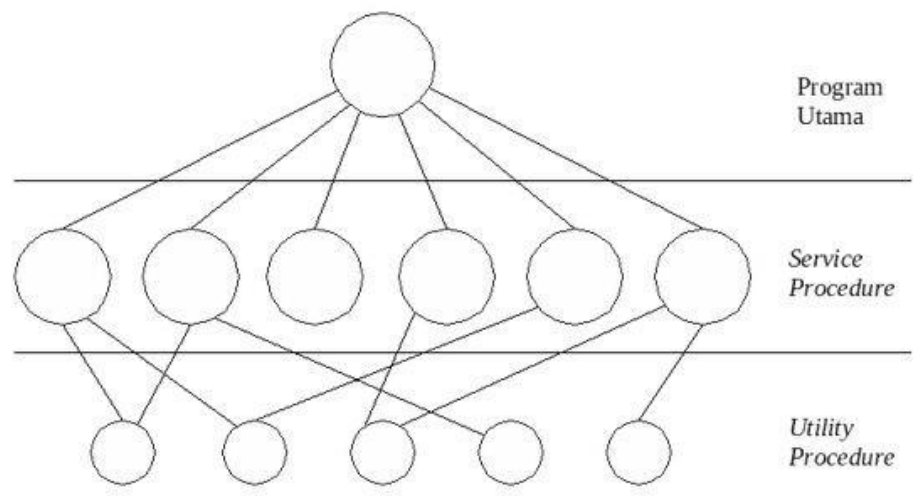

Gambar Model struktur monolitik sistem operasi 
Pada model ini, tiap-tiap sistem call memiliki satu service procedure. Utility procedure mengerjakan segala sesuatu yang dibutuhkan oleh beberapa service procedure, seperti mengambil data dari user program.

Mekanisme dan prinsip kerja model struktur monolitik sistem operasi ini adalah sebagai berikut:

1. User program melakukan "trap" pada karnel

2. Intruksi berpindah dari user mode ke monitor

mode dan mentransfer control ke sistem operasi.

3. Sistem operasi mengecek parameter — parameter dari pemanggilan tersebut, untuk menentukan sistem call mana yang memanggil.

4. Sistem operasi menunjuk ke suatu table yang berisi slot ke-k yang menunjuk sistem call K (Kontrol).

5. Kontrol akan dikembalikan kepada user program, jika sistem call telah selesai mengerjakan tugasnya.

Tatanan ini memberikan suatu struktur dasar dari sistem operasi sebagai berikut :

- Program utama meminta service procedure.

- Kumpulan service procedure yang dibaca oleh sistem call.

- Kumpulan utility procedure yang membantu service procedure. 


\section{Ø Keunggulan Sistem Monolitik}

1) Layanan pada satu ruang alamat memory.terhadap job-job yang ada bisa dilakukan dengan cepat karena berada

\section{$\varnothing$ Kelemahan Sistem Monolitik}

1) Pengujian dan penghilangan kesalahan sulit dilakukan karena tidak dapat dipisahkan dan dilokasikan.

2) Sulit dalam menyediakan fasilitas pengamanan. Kurang efisien dalam penggunaan memori dimana setiap computer harus menjalankan kernel yang besar sementara tidak memerlukan seluruh layanan yang disediakan kernel.

3) Kesalahan pemrograman di satu bagian kernel menyebakan matinya seluruh system.

\section{B. SISTEM BERLAPIS}

Sistem operasi dibentuk secara hirarki berdasar lapisan — lapisan, dimana lapisan-lapisan bawa memberi layanan lapisan lebih atas. Lapisan yang paling bawah adalah perangkat keras dan yang paling tinggi adalah user- interface. Sebuah lapisan adalah implementasi dari obyek abstrak yang merupakan enkapsulasi dari data dan operasi yang bisa memanipulasi data tersebut. Struktur berlapis dimaksudkan untuk mengurangi kompleksitas rancangan dan implementasi sistem operasi. Contoh sistem operasi yang menggunakan sistem ini adalah: UNIX termodifikasi, THE, Venus dan OS/2.

\begin{tabular}{lll} 
Lapis-6 & $:$ & user program \\
Lapis-5 & $:$ & device driver dan sceduler \\
\hline Lapis-4 & $:$ & virtual memory \\
Lapis-3 & $:$ & I/O channel \\
\hline Lapis-2 & $:$ & penjadwalan CPU \\
\hline Lapis-1 & $:$ & instruksi interpreter \\
\hline Lapis-0 & $:$ & hardware
\end{tabular}

Gambar model Struktur sistem operasi berlapis 


\section{Kelebihan Sistem Berlapis}

1) Memiliki rancangan modular, yaitu sistem dibagi menjadi beberapa modul \& tiap modul dirancang secara independen.

2) Pendekatan berlapis menyederhanakan rancangan, spesifikasi dan implementasi sistem operasi.

Kelemahan Sistem Berlapis

1) Fungsi-fungsi sistem operasi diberikan ke tiap lapisan secara hati-hati.

\section{KERNEL MIKRO (MIKROKERNEL)}

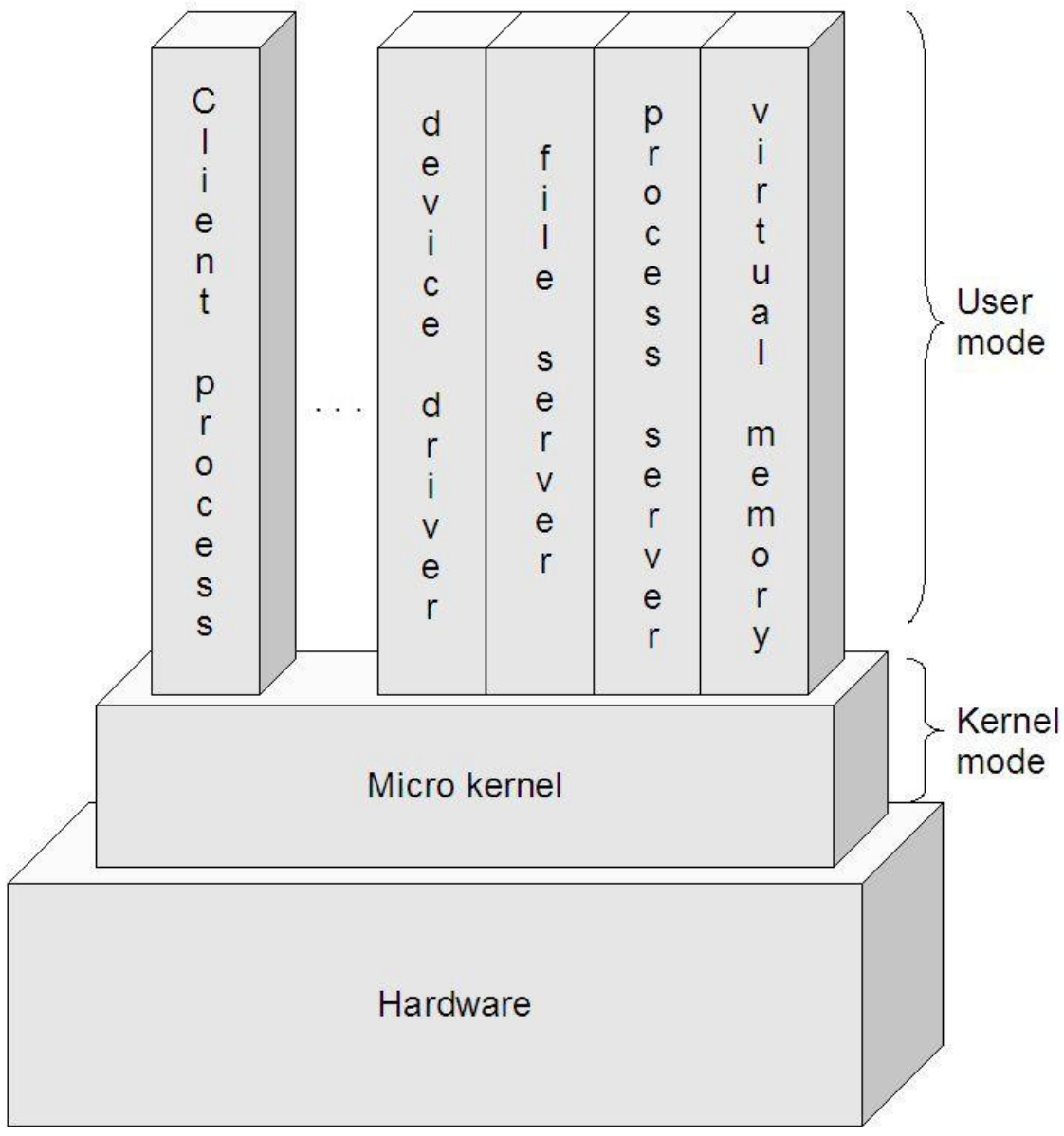




\section{Struktur Mikrokernel}

Metode struktur ini adalah menghilangkan komponen-komponen yang tidak diperlukan dari kernel dan mengimplementasikannya sebagai sistem dan program-program level user. Hal ini akan menghasilkan kernel yang kecil.

Fungsi utama dari jenis ini adalah menyediakan fasilitas komunikasi antara program client dan bermacam pelayanan yang berjalan pada ruang user.

Sistem operasi yang menggunakan micro kernel umumnya secara dramatis memiliki kinerja di bawah kinerja sistem operasi yang menggunakan monolithic kernel. Hal ini disebabkan oleh adanya overhead yang terjadi akibat proses input/output dalam kernel yang ditujukan untuk mengganti konteks (context switch) untuk memindahkan data antara aplikasi dan server.

Contoh Sistem operasi yang menggunakan struktur ini adalah : TRU64 UNIX, MacOSX dan QNX.

\section{Kelebihan Kernel Mikro}

1) kemudahan dalam memperluas sistem operasi

2) Mudah untuk diubah ke bentuk arsitektur baru

3) Kode yang kecil dan lebih aman

Kekurangan Kernel Mikro

1) kinerja akan berkurang selagi bertambahnya fungsi- fungsi yang digunakan. Modular (Modules)

Kernel mempunyai kumpulan komponen komponen inti dan secara dinamis terhubung pada penambahan layanan selama waktu boot atau waktu berjalan. Sehingga strateginya menggunakan pemanggilan modul secara dinamis (Loadble Kernel Modules). Umumnya sudah diimplementasikan oleh sistem operasi modern seperti Solaris, Linux dan MacOSX. 


\section{Section 01}

\section{SISTEM MESIN VIRTUAL}

Konsep dasar dari mesin virtual ini tidak jauh berbeda dengan pendekatan sistem terlapis dengan tambahan berupa antarmuka yang menghubungkan perangkat keras dengan kernel untuk tiap-tiap proses.

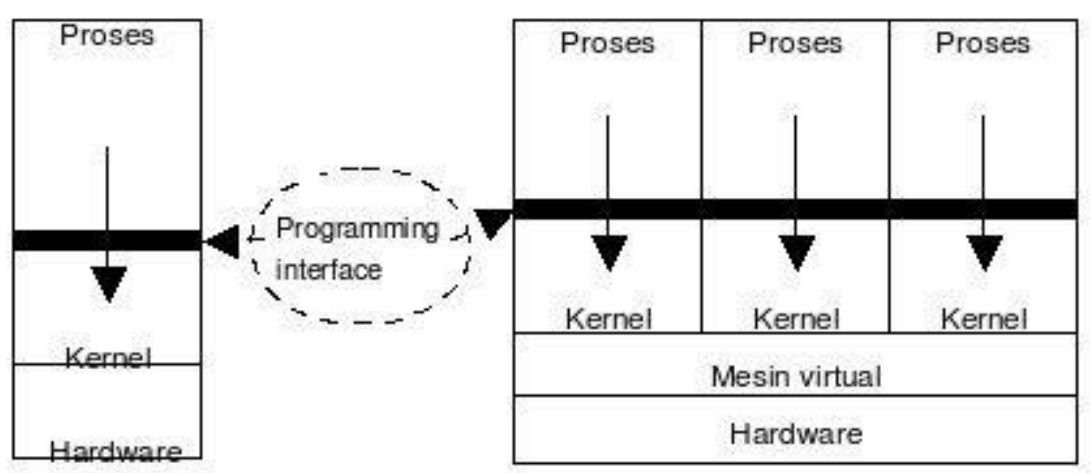

Gambar Model struktur sistem operasi mesin virtual

Mesin virtual menyediakan antar muka yang identik untuk perangkat keras yang ada. Sistem operasi ini membuat ilusi atau virtual untuk beberapa proses, masing-masing virtual proses mengeksekusi prosessornya dan memorinya (virtual) masing-masing.

Mesin virtual hanya dapat berjalan pada monitor- mode jika berupa sistem operasi, sedangkan mesin virtual itu sendiri berjalan dalam bentuk user-mode. Konsekuensinya, baik virtual monitor-mode maupun virtual user-mode harus dijalankan melalaui physical user mode. Hal ini menyebabkan adanya transfer dari usermode ke monitor-mode pada mesin nyata, yang juga akan menyebabkan adanya transfer dari virtual user-mode ke virtual monitor-mode pada mesin virtual.

Contoh sistem operasi yang memakai mesin virtual adalah IBM S/370 dan IBM VM/370. Keuntungan Mesin Virtual

1) Mesin virtual menyediakan proteksi yang lengkap untuk sumber daya system sehingga masing- masing mesin virtual dipisahkan mesin virtual yang lain. Isolasi ini tidak memperbolehkan pembagian sumber daya secara langsung.

2) Sistem mesin virtual adalah mesin yang cocok untuk riset dan pengembangan system operasi. Pengembangan system dikerjakan pada mesin virtual, termasuk di dalamnya mesin 
fisik dan tidak mengganggu operasi system yang normal.

Kekurangan Mesin Virtual

1) Konsep mesin virtual sangat sulit untuk mengimplementasikan kebutuhan dan duplikasi yang tepat pada mesin yang sebenarnya.

E. Client-Server Model:

Sistem operasi merupakan kumpulan proses dengan proses — proses dikategorikan sebagai server dan client, yaitu :

- Server, adalah proses yang menyediakan layanan.

- Client, adalah proses yang memerlukan/meminta layanan.

Proses client yang memerlukan layanan mengirim pesan ke server dan menanti pesan jawaban. Proses server setelah melakukan tugas yang diminta, mengirim hasil dalam bentuk pesan jawaban ke proses client. Server hanya menanggapi permintaan client dan tidak memulai dengan percakapan client. Kode dapat diangkat ke level tinggi, sehingga kernel dibuat sekecil mungkin dan semua tugas diangkat ke bagian proses pemaka. Kernel hanya mengatur komunikasi antara client dan server. Kernel yang ini popular dengan sebutan microkernel.

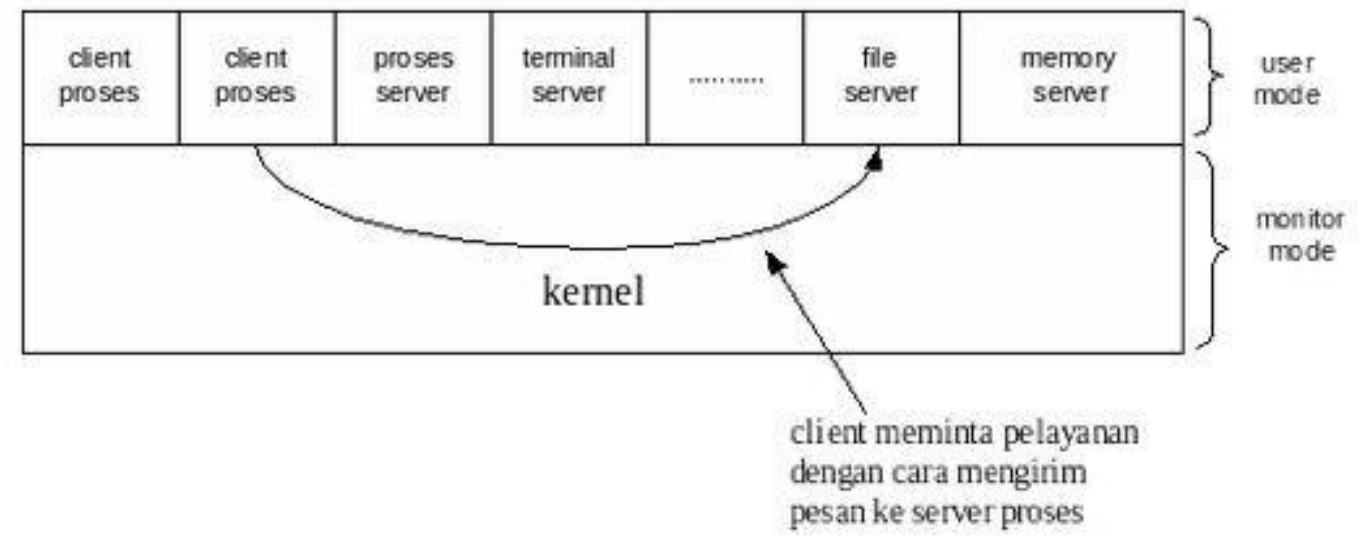

Gambar model Struktur sistem operasi client-server 


\section{Section 01}

\section{Ø Kelebihan Client-Server Model}

1) Pengembangan dapat dilakukan secara modular.

2) Kesalahan(bugs)disatu

3) Subsistem ( diimplementasikan sebagai satu proses ) tidak merusak subsistem subsistem lain, sehingga tidak mengakibatkan satu sistem mati secara keseluruhan.

4) Mudah diadaptasi untuk sistem tersebar.

5) Jika suatu client berkomunikasi dengan server dengan cara mengirimkan pesan, maka server tidak perlu tahu apakah pesan itu dikirim oleh dan dari mesin itu sendiri \{local $\}$ atau dikirim oleh mesin yang lain melalui jaringan.

\section{$\varnothing$ Kekurangan Client-Server Model}

1) Layanan dilakukan lambat karena harus melalui pertukaran pesan.

2) Pertukaran pesan dapat menjadi bottleneck.

3) Tidak semua tugas dapat dijalankan di tingkat pemakai (sebagai proses pemakai).

\section{ID SECURITY}

QWTD4452377-ASP-5244166

\section{KESIMPULAN}

Suatu sistem operasi modern merupakan suatu sistem yang besar dan kompleks sehingga strukturnya harus dirancang dengan hati-hati dan saksama supaya dapat berfungsi seperti yang diinginkan serta dapat dimodifikasi dengan mudah.

Struktur sistem operasi merupakan komponen-komponen sistem operasi yang dihubungkan dan dibentuk di dalam kernel. 
Ada beberapa struktur sistem operasi dan pernah dicoba, diantaranya sebagai berikut: Sistem monolithic , Sistem lapisan, Mesin virtual, Model client server, Referensi

Sistem komputer modern yang semakin komplek dan rumit memerlukan sistem operasi yang dirancang dengan sangat hati-hati agar dapat berfungsi secara optimum dan mudah untuk dimodifikasi.

Struktur sistem operasi merupakan komponen-komponen sistem operasi yang dihubungkan dan dibentuk di dalam kernel.

Sistem monolitik merupakan struktur sistem operasi sederhana yang dilengkapi dengan operasi "dual" pelayanan \{sistem call\} yang diberikan oleh sistem operasi.

Sistem operasi menunjuk ke suatu table yang berisi slot ke-k yang menunjuk sistem call K (Kontrol).

Contoh sistem operasi yang menggunakan sistem ini adalah: UNIX termodifikasi, THE, Venus dan OS/2.

Metode struktur ini adalah menghilangkan komponen-komponen yang tidak diperlukan dari kernel dan mengimplementasikannya sebagai sistem dan program-program level user.

Sistem operasi yang menggunakan micro kernel umumnya secara dramatis memiliki kinerja di bawah kinerja sistem operasi yang menggunakan monolithic kernel.

Contoh Sistem operasi yang menggunakan struktur ini adalah : TRU64 UNIX, MacOSX dan QNX.

Konsep dasar dari mesin virtual ini tidak jauh berbeda dengan pendekatan sistem terlapis dengan tambahan berupa antarmuka yang menghubungkan perangkat keras dengan kernel 
untuk tiap-tiap proses.

Sistem operasi ini membuat ilusi atau virtual untuk beberapa proses, masing-masing virtual proses mengeksekusi prosessornya dan memorinya (virtual) masing-masing.

Hal ini menyebabkan adanya transfer dari usermode ke monitor-mode pada mesin nyata, yang juga akan menyebabkan adanya transfer dari virtual user-mode ke virtual monitormode pada mesin virtual.

Contoh sistem operasi yang memakai mesin virtual adalah IBM S/370 dan IBM VM/370.

1) Mesin virtual menyediakan proteksi yang lengkap untuk sumber daya system sehingga masing- masing mesin virtual dipisahkan mesin virtual yang lain.

2) Sistem mesin virtual adalah mesin yang cocok untuk riset dan pengembangan system operasi. 


\section{REFERENCE}

[1] O. M. Febriani and A. S. Putra,

-Sistem Informasi Monitoring

Inventori Barang Pada Balai Riset

Standardisasi Industri Bandar

Lampung, II. Inform., vol. 13, no. 1,

pp. 90-98, 2014.

[2] A. S. Putra, -Paperplain: Execution

Fundamental Create Application With

Borland Delphi 7.0 University Of

Mitra Indonesia,॥ 2018.
[3] A. S. Putra, -2018 Artikel Struktur

Data, Audit Dan Jaringan Komputer,॥ 2018.

[4] A. S. Putra, -ALIAS MANAGER USED IN DATABASE DESKTOP STUDI CASE DB DEMOS.॥

[5] A. S. Putra, -COMPREHENSIVE SET OF PROFESSIONAL FOR DISTRIBUTE COMPUTING.॥ 
[6] A. S. Putra, -DATA ORIENTED RECOGNITION IN BORLAND DELPHI 7.0.॥

[7] A. S. Putra, -EMBARCADERO DELPHI XE 2 IN GPU-POWERED FIREMONKEY APPLICATION.\|I

[8] A. S. Putra, -HAK ATAS KEKAYAAN INTELEKTUAL DALAM DUNIA TEKNOLOGY BERBASIS REVOLUSI INDUSTRI 4.0.॥

[9] A. S. Putra, -IMPLEMENTASI PERATURAN PERUNDANGAN UU. NO 31 TAHUN 2000 TENTANG DESAIN INDUSTRI BERBASIS INFORMATION TECHNOLOGY.॥ [10] A. S. Putra, -IMPLEMENTATION OF PARADOX DBASE.\| [11] A. S. Putra, -IMPLEMENTATION OF TRADE SECRET CASE STUDY SAMSUNG MOBILE PHONE.\| [12] A. S. Putra, -IMPLEMENTATION PATENT FOR APPLICATION WEB BASED CASE STUDI WWW. PUBLIKLAMPUNG. COM.\| [13] A. S. Putra, -IMPLEMENTATION SYSTEM
FIRST TO INVENT IN DIGITALLY INDUSTRY.\|

[14] A. S. Putra, -MANUAL REPORT \& INTEGRATED DEVELOPMENT ENVIRONMENT BORLAND DELPHI 7.0.॥

[15] A. S. Putra, -PATENT AS RELEVAN SUPPORT RESEARCH.॥ [16] A. S. Putra, -PATENT FOR RESEARCH STUDY CASE OF APPLE. Inc.\|

[17] A. S. Putra, -PATENT PROTECTION FOR APPLICATION INVENT.\|

[18] A. S. Putra, -QUICK REPORT IN PROPERTY PROGRAMMING.॥ [19] A. S. Putra, -REVIEW CIRCUIT LAYOUT COMPONENT REQUIREMENT ON ASUS NOTEBOOK.\| [20] A. S. Putra, -REVIEW TRADEMARK PATENT FOR INDUSTRIAL TECHNOLOGY BASED 4.0.॥ [21] A. S. Putra, -TOOLBAR COMPONENT PALLETTE IN OBJECT ORIENTED PROGRAMMING.\| 
[22] A. S. Putra, -WORKING

DIRECTORY SET FOR PARADOX

7.\| Fakultas Komputer

14

[23] A. S. Putra, -ZQUERY

CONNECTION IMPLEMENTED

PROGRAMMING STUDI CASE PT.

BANK BCA Tbk.\|

[24] A. S. Putra, D. R. Aryanti, and I.

Hartati, -Metode SAW (Simple

Additive Weighting) sebagai Sistem

Pendukung Keputusan Guru

Berprestasi (Studi Kasus: SMK Global

Surya), in Prosiding Seminar

Nasional Darmajaya, 2018, vol. 1, no.

1, pp. 85-97.

[25] A. S. Putra and O. M. Febriani,

-Knowledge Management Online

Application in PDAM Lampung

Province, $\|$ in Prosiding International

conference on Information Technology

and Business (ICITB), 2018, pp. 181187.

[26] A. S. Putra, O. M. Febriani, and

B. Bachry, -Implementasi Genetic

Fuzzy System Untuk Mengidentifikasi

Hasil Curian Kendaraan Bermotor Di

Polda Lampung,\| SIMADA (Jurnal

Sist. Inf. dan Manaj. Basis Data), vol.

1, no. 1, pp. 21-30, 2018.
[27] A. S. Putra, H. Sukri, and K.

Zuhri, -Sistem Monitoring Realtime

Jaringan Irigasi Desa (JIDES) Dengan

Konsep Jaringan Sensor Nirkabel,॥

IJEIS (Indonesian J. Electron.

Instrum. Syst., vol. 8, no. 2, pp. 221-

232.

[28] D. P. Sari, O. M. Febriani, and A.

S. Putra, -Perancangan Sistem

Informasi SDM Berprestasi pada SD

Global Surya,\| in Prosiding Seminar

Nasional Darmajaya, 2018, vol. 1, no.

1, pp. 289-294. 